\title{
The Production of Biofuels from Coconut Oil Using Microwave
}

\author{
A Suryanto ${ }^{1}$, Suprapto $^{2} \&$ Mahfud $^{1}$ \\ ${ }^{1}$ Process Laboratory, Department of Chemical Engineering, Sepuluh Nopember Institute of Technology, \\ Indonesia \\ ${ }^{2}$ Department of Chemical Engineering Faculty of Industrial Technology, Sepuluh Nopember Institute of \\ Technology, Indonesia \\ Correspondence: Mahfud, Process Laboratory, Department of Chemical Engineering, Sepuluh Nopember \\ Institute of Technology, Surabaya, 60111, Indonesia. E-mail: mahfud@chem-eng.its.ac.id
}

Received: May 4, 2015

Accepted: June 5, 2015

Online Published: June 30, 2015

doi:10.5539/mas.v9n7p93

URL: http://dx.doi.org/10.5539/mas.v9n7p93

\begin{abstract}
Biofuels including biodiesel, an alternative fuel, is renewable, environmentally friendly, non-toxic and low emission energy. The raw material used in this work was coconut oil, which contained saturated fatty acids about $90 \%$ with medium chain $\left(\mathrm{C}_{8}-\mathrm{C}_{12}\right)$, especially lauric acid and myristic acid. Reaction was conducted in batch reactor assisted by microwave. The purpose of this research was to study the effect of power and $\mathrm{NaOH}$ catalyst in transesterification enhanced by microwave and to obtain a biofuels (biodiesel and biokerosene) derived from coconut oil. The reaction was performed by mixing oil and methanol with mole ratio of $1: 6$, catalyst concentration of $1 \% \mathrm{w} / \mathrm{w}$ with setting electrical power at $100,264,400,600$ and $800 \mathrm{~W}$. The reaction time was conditioned at of $2.5,5,7.5,10$ and $15 \mathrm{~min}$. The results showed that microwave could accelerate the transesterification process to produce biodiesel using $\mathrm{NaOH}$ catalyst. The highest yield of biodiesel was $97.76 \%$, or $99.05 \%$ conversion at 5 min reaction, meanwhile biokerosene was $48 \%$ after distillation.
\end{abstract}

Keyword: transesterification, biodiesel, biokerosene, coconut oil, microwave

\section{Introduction}

The use ofpetroleumstilldominates theenergyconsumptionin Indonesia, especially in the transport sector. Utilizationof fuelin the transport sectorinthis countryfrom 2003to 2025predicted will be increasingan average $6 \%$ peryear. Indonesia has turned from a net exporter to a net importer ofoil in recent years. It faces heavy challenges since the price of petroleum increases continually. Subsidizedpolicy on petroleum fuelimplemented for decades hasbeenburdensome of government budget. The high price is inevitable to set on international price but it willgreatly affect thepoor people.Toovercomeenergyscarcity, thegovernmentlaunched a regulation for developingof alternativeenergy stipulated in Presidential Instruction No.25year 2006 and Government RegulationNo.5year 2006. Those polices were regulated the nationalenergythatreinforcesthe development of renewable energy and substitution a part of fossil based fuels with biofuels. One of theimportant pointof regulationsis a reductioninfuelconsumptionfrom $54 \%$ to $20 \%$. In an effort toovercome thedeficitof fuel, especially diesel oiland kerosene, the development ofalternative fuelsas analternativeenergyis astrategicchoice. An alternativeenergyis indispensableas the use of petroleum increases year by year(Handayani et al., 2012). One of therenewable sources, which can be developed to be bio-fuel, is a vegetable oil. In Indonesia,biofuelswere still being developed from some renewable materials, which the sources were as follows: foodoils, such aspalmandcoconutoil, non-edibleoils-Jatropha curcas, neemandothers (Demirbas, 2006).Biodiesel, as a renewable fuel, has some advantages compared to fossil fuels as follows: environmentally friendly, biodegradable and lower emission and made from renewable materials, consists of alkyl esters of fatty acids and it can be prepared from vegetable, animal and used cooking oil, or recycled oil (Zabeti et al.,2010).

Vegetable oils that can be developed as a raw material for manufacturing of biodiesel are obtained from palm plants, castor and callophyllum inophyllum fruit (Oliveira et al., 2013). Fatty acids are reacted with an alcohol yielded ester and glycerin (by product) via trans-esterification. Even though glycerin is by product, its price is quite high. Among alcohols is commonly used is methanol for it is cheaper and more reactive than others (Hsiao et al., 2011).

Preparation of biodieselhas beenwidely developedin the conventional manner.Thedevelopment of biodiesel has 
been applying microwave to accelerate thereaction as reviewed by authors (El Sherbiny et al., 2010., Tippayawong et al., 2012). The use ofmicrowaveis an alternativetomanufacture ofbiodiesel enhancing the conversion. The mechanism of heating in microwave application is radiation absorbedbypolar molecules-water, sugars and fats as well asothersubstances. Heatingtakes placesimultaneouslyanduniformlyon the excitedatomsandproduce heatat the same time. Microwaveprovides many advantages as follows: faststartup time, fasterheating, efficient energyandthe lower process cost, easy to monitor, precise, selectiveheatingandthe better quality ofproduct (Jiputti et al., 2006).

Coconut oils consistof variouskinds oftriglyceridefatty acids, which saturatedfattyacid accounted $90 \%$ and are rich of medium chains $\left(\mathrm{C}_{8}-\mathrm{C}_{12}\right)$, especiallylauricacidandmyristicacid. The compositions offattyacids are $6.21 \%$ caprylicacid. $6.15 \%$ capricacid, $51.02 \%$ lauricacid, $18.94 \%$ myristicacid, $8.62 \%$ palmiticacid, $1.94 \%$ acid stearic, $5.84 \%$ oleicacid and $1.28 \%$ linoleicacid(Chowdhury et al., 2007). Coconut oil as a raw material has advantages compared other vegetable oils, it contain $60 \%$ medium chains of fatty acids. Those are possible to obtain otherfuelssuch as kerosene, orjet fuel. This research was aimedtostudy thedevelopment of the process of the preparation of biodieselfromcoconutoilby utilizing the microwavesas an energy sourceand to separate the fractions of products.

\section{Materials and Methods}

\subsection{Materials}

Coconut oil used was the refinery commercial (Barco. Co) from Indonesia. The commercial methanol (in purity $96 \%$ ) was purchased from Brataco. Co. Ltd. (Indonesia) and $\mathrm{NaOH}$, p.a MERCK, (in purity: 99 \%) was obtained from a local chemical supplier (O.V. Chemicals, Co. Ltd).

\subsection{Equipment}

The microwave as source energy was performed to produce biodiesel conducted in a batch reactor. The design of equipment used in this study is shown in Figure1. The reactor was a flat bottom flask made from Pyrex glass equipped with magnetic stirrer. The microwave oven used was Electrolux Microwave EMM2007X with a frequency of $2.45 \mathrm{GHz}$, power output from 0 to 800 Watts and 0 to 30 min time setting. To separate fractions of biofuels employed heating mantle, a three neck flask, condenser and vacuum pump.

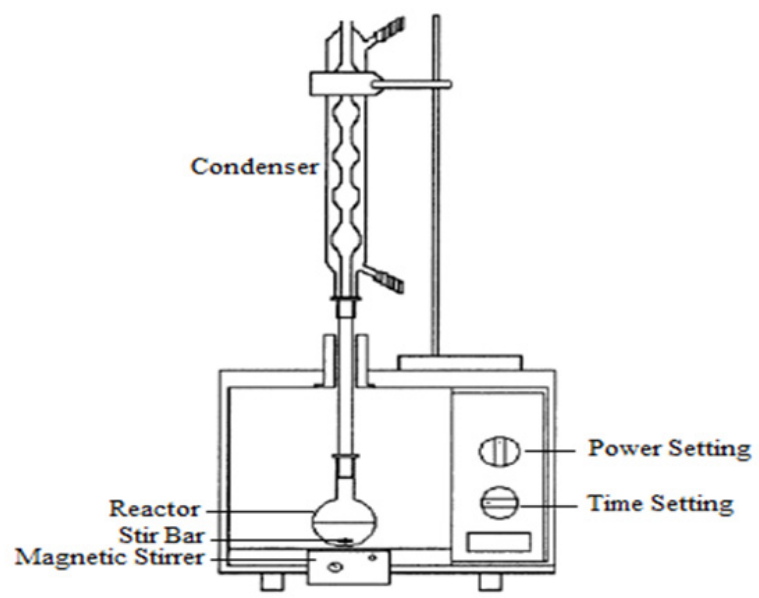

Figure 1. The experiment setup for transesterification process assisted by microwave

\subsection{Experimental Procedure}

\subsubsection{Analysis of FFA Content}

Two grams of oil was added into $25 \mathrm{ml} \mathrm{98 \%} \mathrm{ethanol} \mathrm{inside} \mathrm{Erlenmeyer} \mathrm{flask} \mathrm{by} \mathrm{stirring.} \mathrm{Three} \mathrm{drops} \mathrm{of}$ phenolphthalein indicator were added into solution and titrated with $\mathrm{KOH} 0.1 \mathrm{~N}$, which was done until the color changed to pink. The KOH content was calculated by using an equation (SNI 7182 2012) as follows:

$$
\text { (\%) FFA }=\frac{\text { MW (fa).V.N }}{10 \cdot \mathrm{m} \mathrm{Oil}} \times 100
$$

Where, MW(fa) is molecular weight average of fatty acid and recorded at $226.34 \mathrm{~g} / \mathrm{mole}$ ); $\mathrm{V}$ is $\mathrm{KOH}$ volume needed for titration; $\mathrm{N}$ is normality of $\mathrm{KOH}(0.1 \mathrm{~N})$ and $\mathrm{m}$ is coconut oil weight $(2 \mathrm{~g})$. 


\subsubsection{Transesterification Using Microwave Heating}

Coconutoilwas introduced into the reactorand mixture ofmethanoland $\mathrm{NaOH}$ were added. The molar ratio oil to the methanol was 1:6 and alkaline catalyst used for reaction was $1 \%$.wt. The fifty milli liter coconut oil (with $0.913 \mathrm{gr} / \mathrm{ml}$ ) was fed to the reactor and mixed with 6 mole methanol per running. The solution was reacted in a $250 \mathrm{ml}$ reaction flask with a set reflux tools. Microwave apparatus was modified by making hole on the top of casing to put the condenser. The reaction was started by turning on the microwave power set at $100 \mathrm{~W}$ and 2.5 $\mathrm{min}$. The process was repeated for 264, 400, 600 and $800 \mathrm{~W}$ and 5, 7, 10 and $15 \mathrm{~min}$. After completion, the product was kept in separating funnel for $12 \mathrm{~h}$ for separating the methyl ester and glycerol. The methyl ester was washed using warm water for three times and the product was dried at $110^{\circ} \mathrm{C}$ for $1 \mathrm{~h}$. The methyl ester obtained was proceeded by vacuum distillation to separate biokerosene from biodiesel at $185^{\circ} \mathrm{C}$ and $70 \mathrm{mmHg}$.

\subsubsection{Analysis of Product}

The parameters of biodiesel were analyzed as follows: viscosity (ASTM D445), specific gravity (ASTM D1298), flash point (ASTM D93) and acid number (ASTM D 664) carried out in triplicate. Biodiesel yield, defined as the weight percentage of product over to the initial weight of coconut oil. The concentrations of biodiesel were analyzed by gas chromatography ( 6890 GC) equipped with a capillary column Agilent 19095N-123 INNOWAX, $(30 \mathrm{~m} \times 0.53 \mathrm{~mm} \times 1 \mu \mathrm{l})$ and a flame ionization detector (FID) as well as Helium was the carrier. The conversion was calculated from the content of methyl ester analyzed by GC with the following equation:

$$
\text { Conversion }(\%)=\frac{\left(\mathrm{W}_{\text {biodiesel produced }} / \mathrm{MW}_{\text {biodiesel }} \times \mathrm{C}_{\text {biodiesel }}\right)}{3\left(\mathrm{~W}_{\text {oil }} / \mathrm{MW}_{\text {oil }}\right)} \times 100
$$

MW (molecular weight) of biodiesel and oil were calculated according to the composition of fatty acid shown in Table 1 . The factor 3 in formula was taken for the fact that each triglyceride forming three moles of methyl ester.

\section{Results and Discussion}

\subsection{Characterization of Coconut Oil}

Table. 1 describes the types and compositions of fatty acid characterized by gas chromatography. The highest contents were $41.2 \%$ lauric acid and $23.90 \%$ myristic acid, which were suitable to previous studies (Chowdhury et al., 2007, Eqbal et al., 2011). Prior to used, the properties of coconut oil, free fatty acid, acid number, density and viscosity, were measured as shown in Table 2. When FFA was lesser than 1 percent, the transesterification was conducted one step and bigger than 1 percent, the process was carried out 2 steps (Van Garpen et al., 2004). It was measured that the viscosity of raw material was recorded about $27.5 \mathrm{~mm}^{2} / \mathrm{s}$ as shown in Table 2 .

Table 1. Fatty acid profile of feed stock

\begin{tabular}{lll}
\hline No & Name of fatty acid & Compostion (wt.\%) \\
\hline 1 & Caprylic acid & 0.27 \\
2 & Capric acid & 3.91 \\
3 & Lauric acid & 41.21 \\
4 & Myristic acid & 23.90 \\
5 & Palmitic acid & 16.50 \\
6 & Stearic acid & 3.14 \\
7 & Oleic acid & 9.47 \\
8 & Linoleic acid & 1.61 \\
\hline
\end{tabular}

Table 2. Physicochemical properties of coconut oil

\begin{tabular}{ccc}
\hline Properties & Unit & Coconut Oil Barco \\
\hline Water content & $\%$ & 0.976 \\
Density & $\mathrm{g} / \mathrm{ml}$ & 0.913 \\
Viscosity & $\mathrm{mm}^{2} / \mathrm{s} 40{ }^{\circ} \mathrm{C}$ & 27.5 \\
Free fatty acid & $\%$ & 0.143 \\
Acid number & $\mathrm{mg.KOH} / \mathrm{g} . \mathrm{oil}$ & 0.392 \\
\hline
\end{tabular}




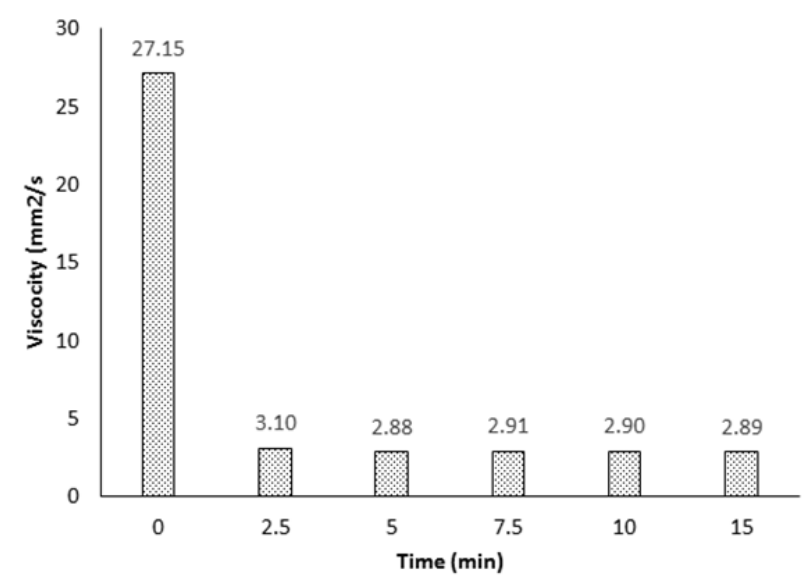

Figure 2. Effect of Reaction time on biodiesel viscosity at 1:6 molar ratio, $1 \% \mathrm{NaOH}$ and power $100 \mathrm{~W}$

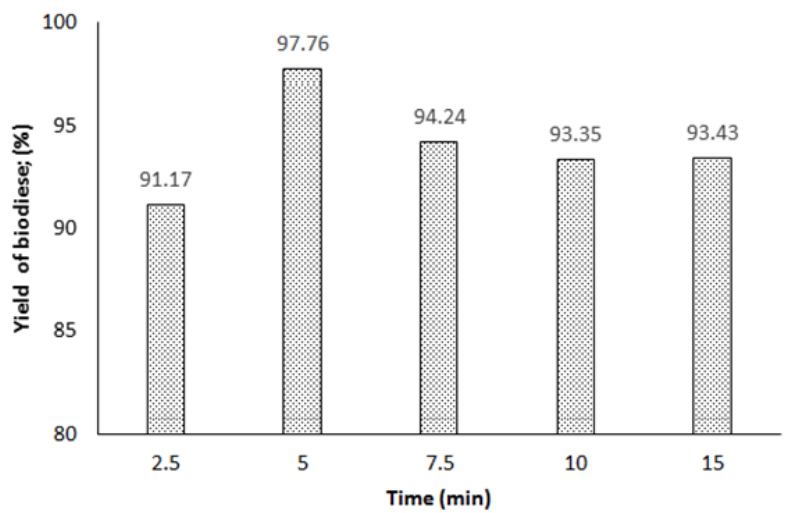

Figure 3. Effect ofreactiontimeon biodiesel yield (1:6 molar ratio, $1.0 \% \mathrm{NaOH}$, and power of $100 \mathrm{~W})$

\subsection{Effect of Reaction Time toward Product Viscosity and Yield}

Experiment was carried out with $1 \mathrm{wt} \% \mathrm{NaOH}$ for various microwave powers in which input power influenced to the amplitude of wave. The greater the power used to generate the microwaves, the bigger the electric field generated (Lidstrom et al., 2001). If the electric field rises, the amplitude of the microwave increases. The rotational speed of polar molecules have a linear relationship to the amplitude of the microwave. The amplitude inclines as polar molecules rotation increases so the heating process is accelerated.

Figure2 shows theeffect ofreaction time power on thetransesterification processto theviscosityof biodiesel. It was found that the viscosity extremely decreased from 27.5 to $2.3 \mathrm{~mm}^{2} / \mathrm{s}$ for 0 to $2.5 \mathrm{~min}$ and was relatively constant for 2.5-15 min. It was indicative that the reaction had completed in $2.5 \mathrm{~min}$. It was surprising that the viscosities of products were relatively similar for all powers as shown in figure. The decrease of viscosity was due to the power directly affected the heating process as reported by authors (Gude et al., 2013).

Figure 3 shows the yield of product obtained respect to reaction time conducted at $100 \mathrm{~W}$. The yields of product significantly increased to $91.17 \%$ at $2.5 \mathrm{~min}$ and $97.76 \%$ at $5 \mathrm{~min}$. After $5 \mathrm{~min}$, the yields slightly decreased and then was relatively constant. This indicated that the longer time did not significantly influence the yield of biodiesel. It was characteristic of biodiesel preparation using microwave that needed less time (Chen et al., 2012).

\subsection{The Effects of Microwave Power on the Yield of Biodiesel}

Figure 4 describes the effect of microwave power on yield of biodiesel conducted at $1 \% \mathrm{NaOH}$ for $5 \mathrm{~min}$. and molar ratio of oil to methanol was 1: 6. Generally, the yield of biodiesel decreased as the power increased, which was similar to other works (Galema.1997). The increase of microwave power caused the damage of organic substances, such as triglycerides (Saifuddin et al., 2004). The energy required for the microwave method was 23 times lower than that of the conventional method (Pathil et al., 2010). This case showed that the use of microwave in transesterification reaction with $\mathrm{NaOH}$ was better conducted within a low power $100 \mathrm{~W}$. It was found that preparation biodiesel assisted microwave was conducted in short time, 5 min compared to 
conventional technique taken for $1 \mathrm{~h}$ as previously published study (Chen et al., 2012).

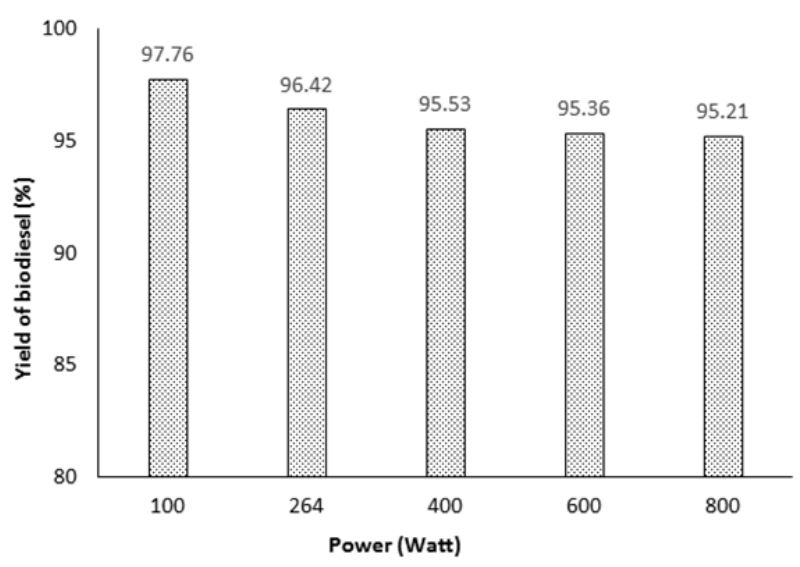

Figure 4. Effect ofmicrowaves power onbiodiesel production

The highest yield of biodiesel obtained was $97.65 \%$ at $100 \mathrm{~W}$ for molar ratio of oil to methanol 1:6. While, the yields at 264 until $800 \mathrm{~W}$ decreased to $96.42 \%$ to $95.21 \%$. The decrease of yield caused by the inclining of temperature in short time so methanol was continually evaporated and condensed, which triggered the saponification reaction. The improvement of power increased the rate of microwave beams so that excitation occurred in the molecules. The preparation conducted above $60^{\circ} \mathrm{C}$ using $\mathrm{NaOH}$ was not effective because of the rivalry between transesterification and saponification reactions as previously published by Dorado, et al, (2004). Therefore, the process of transesterification reaction using $\mathrm{NaOH}$ in microwaves should be carried out with shorter time, which was less than $60 \mathrm{~min}$. The heating by microwaves in liquid and solids compounds occurred, where the electromagnetic energy was transferred into heat. The heating effect of microwave forced dipoles and ions to rotate from slow to fast motions.

\subsection{Separation of Biodiesel and Biokerosene}

The methyl ester prepared was proceeded to separation process to obtain biokerosene. The separation was conducted heating conditioned at $185^{\circ} \mathrm{C}$ and $70 \mathrm{mmHg}$. The heating was maintained until the distillate dropped. The amount of methyl esters separated was $100 \mathrm{ml}$ and biokerosene was $47.5 \mathrm{ml}$ after heating for $45 \mathrm{~min}$. The biokerosene was evaporated and condensed to be distillate, meanwhile methyl ester was not escaped from bottom distiller for its boiling point was higher than that distillate. The product, which was not evaporated was golden yellow, and distillate was more transparent.

\subsection{Biodiesel Properties of Coconut Biodiesel}

The quality of the product is determined by several parameters, such as cetane number, kinematic viscosity, density, and others. Table 3 describes the comparisons of biodiesel properties obtained compared to those of biodiesel ISO standard. It was found that the product of methyl ester meets the standard of parameters determined. In this work, the measurement of biodiesel referring to ASTM (American Society for Testing and Materials). Authors had carried out the combustion testing for biokerosene, which was filled in a torch. The combustion showed the good result since there was not smoke appearing. It was indicative that the combustion process was perfect and the fuel was environmentally friendly.

Table 3. Comparisons biodiesel production with biodiesel standard

\begin{tabular}{lcccc}
\hline Physical properties & Unit & Sample & (SNI-2012) & $($ ASTM) \\
\hline Relative density & $\mathrm{gr} / \mathrm{ml} 25^{\circ} \mathrm{C}$ & 0.86 & $0.85-0.89$ & - \\
Viscosity & $\mathrm{mm}^{2} / \mathrm{s}, 40^{\circ} \mathrm{C}$ & 2.88 & $2.30-6.0$ & $1.90-6.0$ \\
Sulfur content & $\%$ & 0.0072 & $<100$ & - \\
Yield & $\%$ & 97.76 & - & - \\
Acid number & $\mathrm{mg} . \mathrm{KOH} / \mathrm{gr}$ & 0.056 & $<0.80$ & $<0.80$ \\
Water content & $\%$ & 0.049 & $<0.05$ & $<0.05$ \\
\hline
\end{tabular}




\section{Conclusion}

The biofuels, biodiesel and biokerosene were successfully prepared using the microwave, which decreased the reaction time. It was found that the greater the power used was the lower of yield of biodiesel obtained. The highest yield was $97.76 \%$, or $99.05 \%$ conversion at power $100 \mathrm{~W}$ for $5 \mathrm{~min}$ using $1 \% \mathrm{NaOH}$.The methyl esterbiodieselandbiokerosene were separated applying vacuum distillation at $185^{\circ} \mathrm{Cand}$ distillate (biokerosene fraction) obtained was $48 \%$. In general, the quality of products meets the standard numbers as required by ASTM.

\section{References}

Chen, K. S., Lin, Y. C., Hsu, K. H., \& Wang, H. K. (2012). Improving Biodiesel Yield from Waste Cooking Oil by Using Sodium Methoxide and a Microwave Heating System. Energy, 38, 151-158. http://dx.doi.org/10.1016/j.energy.2011.12.020

Chowdhury, K., Banu, L. A., \& Khan, S. A. L. (2007). Studies on the Fatty Acid Composition Of Edible Oil, Bangladesh J. Sci.Ind.Res, 42(3), 311-316. IFST, BCSIR, Dhaka-1205, Bangladesh.

Dorado, M. P., Ballesteros, F., Lopes, F. J., \& Mittelbach, M. (2004). Optimization of Alkali Catalyzed Transeterification of Brassica Carinata Oil for Biodiesel Production. Energy Fuel, 18, 77-83.

El Sherbiny, S., Refaat, A. A., \& El Sheltawy, A. T. (2010). Production $\backslash$ of Biodiesel using Microwave Technique. Journal of Advance Research, 1, 309-314. http://dx.doi.org/j.jare.2010.07.003

Galema, A. S. (1997). Microwave Chemistry. Chemical Society Reviews, 26, 233-238. http://dx.doi.org/10.1039/cs9972600233

Gude, V. G., Patil, P., \& Guerra, E. M. (2013). Microwave Energy Potential for Biodiesel Production. Mississippi State University, Chemistry Central, USA, 2013. http://dx.doi.org/10.1186/2043-7129-1-5

Handayani, A., \& Ariyanti, D. (2012). Potency of Solar Energy Aplications in Indonesia. Int. Journal of Renewable Energy Development, 1(2), 33-38.

Hsiao, M. C., Lin, C. C., \& Chang, Y. H. (2011). Microwave Irradiation Assisted Transesterification of Soybean Oil to Biodiesel Catalyzed by Nanopowder Calcium Oxide. Fuel, 90, 1963-1967. http://dx.doi.10.1016/j.fuel.2011.01.004

Jiputti, J., Kitiyanan, B., Rangsunnivit, P., Bunyakiat, K., Attnatho, L., \& Jenvanipanjakul. P. (2006). Transesterification of Kernel Oil and Crude Coconut Oil by Different Solid Catalysts. Chemical Engineering Journal, 116, 61-66.

Lidstrom, P., Tierney, P., Wathey, B., \& Westman, J. (2001). Microwave Assisted Organic Synthesis-A Review. Tetrahedron, 57, 9225-9283.

Oliveira, A. N., Costa, L. R. S., Pires, L. H. O., Nascimento, L. A. S., Angelica, R. S., Costa, C. E. F., Zamian, J. R., \& Filho, G. N. R. (2013). Microwave Assisted Preparation of a New Esterification Catalyst from Wasted Flint Kaolin. Fuel, 103, 626-631. http://dx.doi.org/10.1016/j.fuel.2012.07.017

Pathil, P. D, Gude, V. G, Camacho, L. M., \& Deng, S. (2010). Microwave Assisted Catalytic Transesterification of Camela Sativa Oil. Energy Fuels, 24, 1298-1304. http://dx.doi.org/10.1021/ef9010065

Saifuddin, N., \& Chua, K. H. (2004). Production of Ethyl Ester from Used Frying Oil: Optimization of Transesterification Process Using Microwave Irradiation. Malaysian J. Chem, 6, 77-82.

Tippayawong, N., \& Sittisun, P. (2012). Continuous Flow Transesterification of Crude Jatropha Oil with Microwave Irradiation. Scientia IranicaB, 19(5), 1324-1328. http://dx.doi.org/10.1016/j.scient.2012.08.004

Zabeti, M., Daud, W. M. A.W., \& Arroua. M. K. (2010). Biodiesel Production using Alumina Supported Calsium Oxide: An Optimization Study. Fuel Processing Technology, 91, 243-248. http://dx.doi.org/10.1016/j.fuproc.2009.10.004

\section{Copyrights}

Copyright for this article is retained by the author(s), with first publication rights granted to the journal.

This is an open-access article distributed under the terms and conditions of the Creative Commons Attribution license (http://creativecommons.org/licenses/by/3.0/). 